Portland State University

PDXScholar

\title{
The Impact of Coordination by a Child Abuse Committee on Community Services to Battered Children
}

\author{
Grace Jackson Anders \\ Portland State University \\ Rebekah M. Burton \\ Portland State University
}

Follow this and additional works at: https://pdxscholar.library.pdx.edu/open_access_etds

Part of the Family, Life Course, and Society Commons, Social Control, Law, Crime, and Deviance Commons, and the Social Work Commons

Let us know how access to this document benefits you.

\section{Recommended Citation}

Anders, Grace Jackson and Burton, Rebekah M., "The Impact of Coordination by a Child Abuse Committee on Community Services to Battered Children" (1972). Dissertations and Theses. Paper 1729.

https://doi.org/10.15760/etd.1728

This Thesis is brought to you for free and open access. It has been accepted for inclusion in Dissertations and Theses by an authorized administrator of PDXScholar. Please contact us if we can make this document more accessible: pdxscholar@pdx.edu. 
AN ABSTRACT OF THE RESEARCH PRACTICUM OF Grace Jackson Anders and Rebekah M. Burton for the Master of Social Work degree, May 15, 1972.

TItle: The Impact of Coordination by a Child Abuse Committee on Community Services to Battered Children.

The Child Abuse Committee at the University of Oregon Medical School has assumed a coordinating role as an attempt to provide more effective service to abused children and their families. This research report is a follow up to a 1970 study by Matusak which evaluated the effectiveness of the Committee. The Matusak study seemed to indicate that, because of Committee action resulting in appropriate intervention and services, definite improvement in the situation of the children in the study was seen. This study follows the children from the 1970 study one year later and makes further comparisons of child abuse cases seen at the hospital in 1971. The results of this study fail to support the Matusak findings. A decreased percentage of children in the 1970 study group have maintained their level of improvement one year later and an even lower percentage of the 1971 study group are improved. More children have been left in their owm homes than in 1970 but there is little to indicate that the family functions any more adequately than at the time of abuse. The findings seem to reflect a need for reevaluation of management and treatment practices in child abuse cases. It appears that responsibility and authority for coordination should be placed with a single agency and that more specialized services be provided by experienced staff. 
THE IMPACT OF COORDINATION BY A CHIL ABUSE COMMTTEE

$\mathrm{ON}$

COMMUNITY SERVICES TO BATTERED CHIIDREN

by

GRACE JACKSON ANDERS

REBEKAH M. BURTON

A report submitted in partial fulfillment of the requirements for the degree of

MASTER OF

SOCIAL WORK

Portland State University

1972

APPROVED:

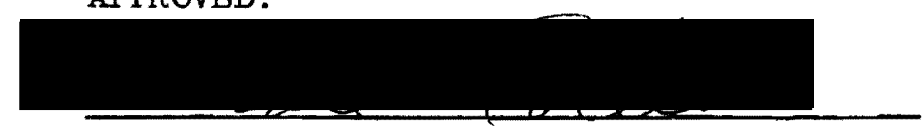

Dale Poteet, Chairman

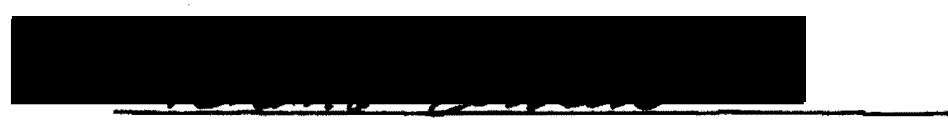

Richard Olmsted, M.D. 
TABLE OF CONTENTS

PAGE

LIST OF TABLES . . . . . . . . . . . . . . . . . . . . iii

TEXT

Introduction ...................... 1

Organization and Function of the Child Abuse Committee . . . 3

Methodology . . . . . . . . . . . . . . . 5

Summary of Data . . . . . . . . . . . . . . 9

Discussion ................... 20

Summary and Recommendations . . . . . . . . . . 28

BIBLIOGRAPHY . . . . . . . . . . . . . . . . 32

APPENDIX ....................... 34 
LIST OF TABIES

TABIE

PAGE

I Study Cases, 1970 and 1971 ............. 9

II Age Distribution, 1970 and 1971 Study Groups . . . . 9

III Age Distribution by Sex of Child, 1970 and 1971 Study Groups .................... 10

IV Age Distribution, Serious - Non-Serious Injury, 1970 and 1971 Study Groups ........... 11

V Seriousness of Injury and Family Composition, 1970 and 1971 Study Groups ... . . . . . . . . . 12

VI Child Abuse Report Related to Serious - Non-Serious Injury, 1970 and 1971 Study Groups. . . . . . 12

VII Children Made Juvenile Court Wards as a Result of Report of Injury, 1970 and 1971 Study Groups. . .

VIII Children Removed by Court Order as a Result of Injury, 1970 and 1971 Study Groups. . . . . . . . . . 14

IX Families Receiving Help as a Result of Child Being Removed, 1970 and 1971 Study Groups ....... 15

$\mathrm{X}$ Children in Own Homes, Improvement as Related to Seriousness of Injury and Agency Help, 1970 and 1971 Study Groups ................ .

XI Improvement of Child's Situation in Relation to Agency Help, 1970 and 1971 Study Groups

XI Continued . . . . . . . . . . . . . . . . .

XII Seriousness of Injury Related to Improvement or Lack of Improvement, 1970 and 1971 Study Cases. . . . 
There are many threats to the welfare of children but none so ominous as the abuse inflicted upon a child by his parent or caretaker. The prevalence of child abuse and neglect has become increasingly apparent in recent years. Recognition of this as a major problem in our society has led to mandatory reporting laws in every state of the union and to widespread publicity.

A major goal of those concerned with this problem must be not only the early identification of victims of abuse and provision for their prom tection but also the means to help those parents who have a potential for better child rearing.

Members of the Child Abuse Committee at the University of Oregon Medical School, recognizing that the needs of the abused child and his family were not being met merely by the identification of abuse and the provision of medical treatment, in 1970 assumed a coordinating role in the provision of service following the release of the child from the hospital. Their request for an evaluation of their effectiveness as a committee resulted in the Matusak study. ${ }^{1}$ This study produced some interesting and revealing facts concerning the effect of action by the committee in the outcome of cases considered. The improvement in the 1970 cases over those in 1969 appeared to be related to the intervention and follow through by the Committee.

Dr. Richard Olmsted, Committee Chairman, felt an extension of the study would help to determine and to document the long range effect of

${ }^{1}$ Marguerite Matusak, "Follow Through Services for Child Abuse Cases", (unpublished M.S.W. research practicum, Portland State University, 1971). Hereafter referred to as the Matusak study. 
Committee action. He requested a follow-up study with the same criteria to be applied in making a comparison of 1970 and 1971 cases. Also of particular interest to him was an extension of the study which might develop data related to feelings and attitudes of parents regarding services offered at the time of and following the abuse incident.

The researchers have found no evidence of a continuing trend in improvement of the abused child. On the contrary, a decreased percentage of the 1970 study group shows improvement in 1971 and an even lower percentage of the 1971 study group are improved.

This seems to reflect a need for a reevaluation of management and treatment practices in child abuse cases. Since child abuse is a widespread problem, not limited to cases seen at the University of Oregon Medical School, it appears that responsibility and authority for coordination should be placed with a single agency. 
CRGANIZATION AND FUNCTION OF THE CHIL ABUSE COMMITTEE

The Child Abuse Committee ${ }^{2}$ at the University of Oregon Medical School ${ }^{3}$ operates under the basic premise that someone must assume responsibility for children who are thought to have been abused 4 by (1) determining the facts; (2) assessing the child's need for protection and making provision for it; and (3) helping the parents, if possible, to become better parents.

Professional and agency representation on the Committee has remained essentially the same as reported in the Matusak study. The inter-departmental committee is chaired by Dr. Olmsted, Chairman, Department of Pedlatrics at UaMs. Other members are: Dr. William Clark, Director of Inpatient Pediatrics; Dr. Emily Tufts, liaison-coordinator for Pediatrics Outpatient Department; Mrs. Joan Hazelrigg, Social Worker; Mrs. Helen Erlandson, Public Health Nursing Coordinator; Miss Mary Amdall, Pediatric Psychiatric Nurse and Dr. Elizabeth King, Medical Psychologist. Also on the Committee is Mrs. Anne Wilson, Juvenile Court Counselor. Other Uavs staff members and professional people from the community are invited to participate in Committee deliberations when warranted. Public Health and Children's Services Division are agencies frequently represented.

Whenever a child is seen at either inpatient or outpatient departments at the Medical School and abuse is suspected, the matter is reported

2 Hereafter referred to as the Committee.

3 Hereafter referred to as UOMS.

${ }^{4}$ Child Abuse as defined by Oregon Revised Statutes is a) "any physical injury to a child caused by blows, beating, physical violence... . where there is some cause to suspect that the injury was intentionaliy or wantonly inflicted or b) neglect, including malnutrition, which leads to physical harm." 
to the Comnittee for its consideration. The Committee meets weekly for (1) presentation of new cases and to consider treatment plans and (2) to review progress reports on active cases. Cases are followed until such a time as it is reasonable to believe that the safety, health and welfare of the child is assured. Should the child move from the community an effort is made to alert appropriate agencies in the new comminity of the circumstances which have been seen as cause for concern. 


\section{METHODOLOGY}

A review of medical records of all cases of child abuse seen at UOMS in 1969 and 1970 provided the basis for determination of the study population in the Matusak study. The selection of cases to be included in the study was based on hospital responsibility for follow up services as determined by specific criteria. These criteria are: (1) Identification of abuse or neglect by UOMS hospital staff while providing regular medical care, (2) Recorded medical knowledge of the child at UOMS prior to injury, (3) A transfer to UOMS by another medical facility after their identification of abuse.

Since this study was designed as a follow up to the Matusak study, an attempt was made to apply the same criteria to the selection of the 1971 study cases. A review was made of all cases of child abuse seen at UOMS in the calendar year 1971. These cases included 33 children who were hospitalized at UOMS Hospital, 4 children seen and treated in the Emergency Room and 16 children seen and treated in the Outpatient Clinic. Each of the 53 cases had been presented to the Committee during the year. They were considered for varying periods of time, from one meeting to several months.

The primary purpose of the initial review of cases was to screen out those which did not meet the criteria for hospital responsibility: Twenty cases were excluded from the study as not meeting the criteria for selection. The remaining 33 cases constitute the study population for 1971.

As each of the 1971 study cases was reviewed data was collected. This included information required for comparison with the 1970 cases, such as child's age at time of admission, whether hospitalized, seriousness 
of injury, family make up, whether Child Abuse Report ${ }^{5}$ was filed, removal from home, any reference to law enforcement or social agency involvement. During the last three months of 1971 the data was extracted by the researchers from hospital records, including medical and social service, and from minutes of the Committee meetings. From September through December 1971, attendance at Committee meetings allowed the researchers to be aware of new case presentations as well as to be closely in touch with progress of cases being followed by the Committee. In March 1972 they made a second review of the medical chart for each child in the study.

A check was made with those agencies and in those counties where there was reason to believe there might be knowledge of a particular child. This was accomplished by sending a list of study cases to these agencies. Included were: Juvenile Courts in Multnomah, Marion and Lane counties; also Women's Protective Division of Portland, the Multnowah County Sheriff's Office, Public Health Departments in Multnomah and Clackamas Counties, Children's Services Division in Multnomah, Clackamas, Marion and Lane Counties. A list of all 53 cases was sent to the Central Registry maintained by the Children's Services Division of the State of Oregon to determine on which children a Report had been filed.

With the information resulting from these various sources the researchers were able to make a determination of the agency seeming to have primary responsibility for service to each case. In order to assess the effect of follow through services and to determine the present status of each study child in relation to abuse, contact was made with the agency offering help. An effort was made to talk to the agency person specifically responsible

5 Hereafter referred to as the Report. 
for each child's case.

Areas of information needed to make an evaluation of the outcome of each case were (1) whether the injury resulted in removal of the child and if he was made a ward of the Juvenile Court, (2) where the child is presently living, (3) if help ${ }^{6}$ is being given to the family and by whom, (4) present adjustment of the family. Also of interest was whether there had been a repeat incident of abuse.

In respect to the 1970 cases in the Matusak study, essentially the same procedures were followed in compiling data to be used in determining the present status of these children and in evaluating their situation in relation to continuing agency help.

Additional data were gathered and compiled as an extension to the Matusak study. Included were comparisons of the relationship of serious injuries to age, sex, the filing of a Report and the situation outcome. The data for these comparisons were recorded concurrently with that previously discussed in this section.

A questionnaire ${ }^{7}$ was designed to be used with parents of children in the 1970 study group, the goal being to gain an understanding of their perception of the incident of abuse and the services offered to them. With this purpose in mind, the questionnaire covered these areas as seen by the parents: (1) their understanding of, a) the reason for hospitalization, b) the diagnosis at discharge, (2) the provider of help both in the hospital and following discharge, (3) the effectiveness of help offered, (4) feelings about the child, particularly any change in feelings

${ }^{6}$ Help is defined as how an agency views service to a case. $7^{7}$ See Appendix A. 
since the incident of abuse, (5) their recommendations for improvement of sarvices in ohild abuse cases.

It planned that in March 1972 home visits would be made by one of the researchers for the purpose of oonducting the interview. Every offort was made to seoure ourrent addresses. This wes accomplished for the most part through the agency having the most recent knowledge of the 0ase. In each case the agenoy person wes consulted as to thoir view of the advisability of such a visit. In no case was a home visit planned without concurrence from the agency staff person. In all but one instance the staff person felt that the information to be obtained would bo valuable in terms of improving service to families of victims of child abuse. 
Table I shows a tabulation of data which provides a comparison of the number of cases in 1971 and 1970.

TABIE I

STUDY CASES - 1970 AND 1971

$\begin{array}{lcc} & 1970 & 1971 \\ \text { Total Cases Reviewed } & 59 & 53 \\ \text { Excluded From Study } & 32 & 20 \\ \text { Total Study Cases } & 27 & 33\end{array}$

Table II presents the age distribution of children in this study and makes a comparison to those in the Matusak study. Two-thirds of those in this study were less than two years of age. Whereas the total number of children under two was comparable in 1970 and 1971, there was an increase in 1971 of children under one year.

TABLE II

AGE DISTRIBUTION

1970 AND 1971 STUDY GROUPS

\begin{tabular}{cccccc} 
Age & \multicolumn{2}{c}{1970} & \multicolumn{2}{c}{1971} \\
Under 1 year & No. & \% & №. & \% \\
$1-2$ & 10 & $37 \%$ & 15 & $46 \%$ \\
$2-3$ & 8 & 30 & 6 & 18 \\
$3-4$ & 2 & 7 & 2 & 6 \\
$4-5$ & 2 & 7 & 2 & 6 \\
$5-6$ & 0 & 0 & 2 & 6 \\
$6-12$ & 1 & 4 & 2 & 6 \\
Over 12 & 3 & 11 & 4 & 12 \\
& 1 & 4 & 0 & 0 \\
TOTAIS & 27 & $100 \%$ & 33 & $100 \%$
\end{tabular}


Table III presents age distribution by sex of child, making a comparison between the 1970 and 1971 study groups. There was little difference in the sex distribution for the total study population in either this study or the Matusak study. By age distribution the combined study shows a higher number of males than females under two years. Comparing this age group for the two study years we find in the 1971 study the greater number of males is under one year whereas in the 1970 study a greater number of males in the one to two range.

TABLE III

AGE DISTRIBUTION BY SEX OF CHIID

1970 AND 1971 STUDY GROUPS

\begin{tabular}{|c|c|c|c|c|c|c|}
\hline & \multicolumn{2}{|c|}{1970} & \multicolumn{2}{|c|}{1971} & \multicolumn{2}{|c|}{$1970 \& 1971$} \\
\hline Age & $\underline{M}$ & $E$ & $\underline{M}$ & $\underline{F}$ & $\underline{M}$ & $\underline{F}$ \\
\hline Under 1 & 5 & 5 & 9 & 6 & 14 & 11 \\
\hline $1-2$ & 7 & 1 & 3 & 3 & 10 & 4 \\
\hline $2-3$ & 0 & 2 & 2 & 0 & 2 & 2 \\
\hline $3-4$ & 0 & 2 & 1 & 1 & 1 & 3 \\
\hline $4-5$ & 0 & 0 & 0 & 2 & 0 & 2 \\
\hline $5-6$ & 1 & 0 & 1 & 1 & 2 & 1 \\
\hline $6-12$ & 1 & 2 & 3 & 1 & 4 & 3 \\
\hline Over 12 & $\underline{0}$ & 1 & $\underline{0}$ & 0 & 0 & 1 \\
\hline TOTALS & 14 & 13 & 19 & 14 & 33 & 27 \\
\hline
\end{tabular}

The relationship of Serious - Non-serious injury to age is shown in Table IV. Serious injury refers to injuries which could be life threatening, or cause permanent damage (such as fractures, burns or severe malnutirtion.) Non-serious injury refers to bruises, lacerations and contusions usually requiring only outpatient treatment. In looking at the 
increased number of children under one in the 1971. study we find $86.6 \%$ received serious injury. The Matusak study shows $70 \%$ of this same age group received serious injury, an increase of $16.6 \%$.

TABLE IV

AGE DISTRIBUTION

SERIOUS - NON-SERIOUS INJURY

1970 AND 1971 STUDY GROUPS

1970

Age

Under 1 year

$1-2$

$2-3$

$3-4$

$4-5$

$5-6$

$6-12$

Over 12

TOTALS
Non-

1970
Non-
Serious Serious

\author{
1971 \\ Non- \\ Serious Serious
}


TABLE V

SERIOUSNESS OF INJURY AND FAMILY COMPOSITION

1970 AND 1971 STUDY GROUPS

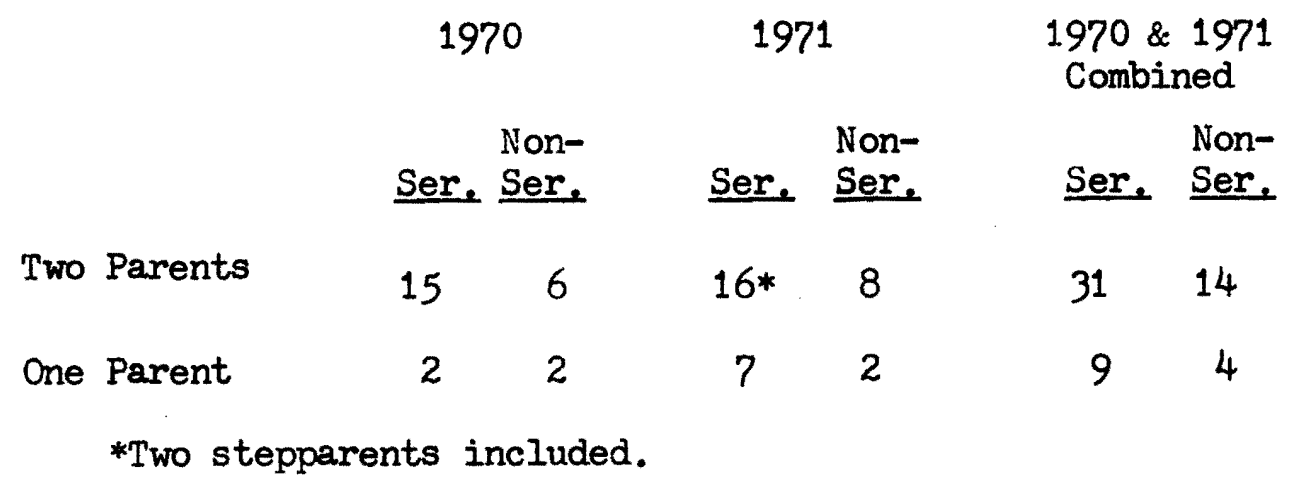

Table VI relates the filing of a Report to serious - non-serious injury. Reports of injury were filed in $66.7 \%$ of the cases in this study. This percentage is comparable to the $67 \%$ reported in the Matusak study. Tabulation of data reveals that the filing of a report is not necessarily based on the seriousness of the injury. In 1971 a report was filed on 60.9\% of the children receiving serious injury. This was only a slight increase over the $57.9 \%$ of children with serious injury on whom reports were filed in 1970.

\section{TABLE VI}

CHIID ABUSE REPORT RELATED TO SERIOUS - NON-SERIOUS INJURY 1970 AND 1.971 STUDY GROUPS

$\begin{array}{lcc} & 1970 & 1971 \\ \text { Serious Injury, Reported } & 10 & 14 \\ \text { Serious Injury, Not Reported } & 9 & 9 \\ \text { Non-Serious Injury, Reported } & 4 & 8 \\ \text { Non-Serious Injury, Not Reported } & 4 & 2\end{array}$


As shown in Table VII there seems to be a trend toward a decreasing number of Juvenile Court wardships in relation to reports filed. In this study $21.3 \%$ of the cases were reported and also made court wards. Another $39.4 \%$ were reported but not made Juvenile Court wards. An additional $6 \%$ were reported but died from their injuries during hospitalization. There were almost twice as many children who were reported and made court wards in 1970.

\section{TABLE VII}

CHILDREN MADE JUVENILE COURT WARDS AS A RESULT OF REPORT OF INJURY IN 1970 AND 1971 STUDY GriOUPS

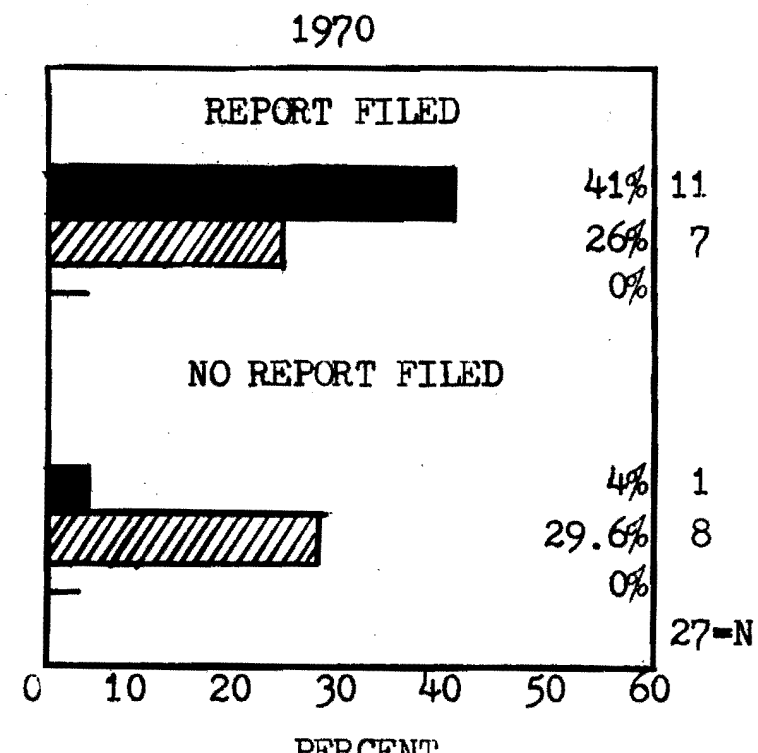

PERCENT

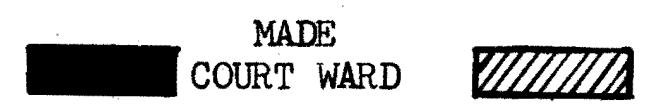

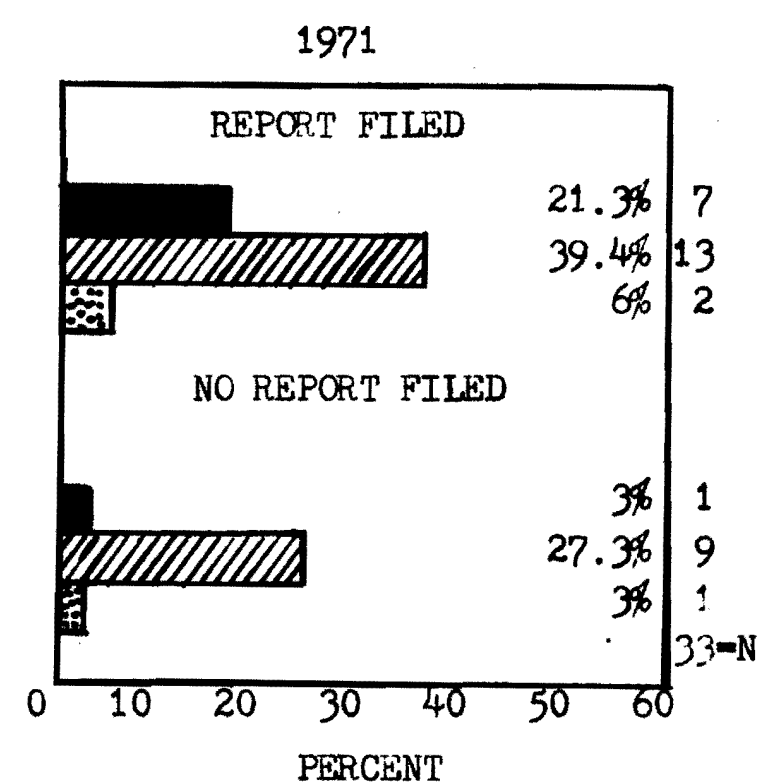

NOT MADE COURT WARD

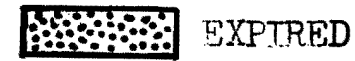

The number of children removed from parental homes by court order as a result of their injury is shown in Table VIII. Fewer of the hospitalized 
ized children were removed in 1971 than in 1970. However, when one adds the percentage of those who died to those who were removed in 1971 the combined total of $36.4 \%$ comes closer to the $45 \%$ removed in 1970 . There was a comparable decrease in the number of non-hospitalized children removed.

TABIE VIII

CHILIREN REMOVED BY COURT ORDER

AS A RESULT OF INJURY

1970 AND 1971 STUDY GROUPS
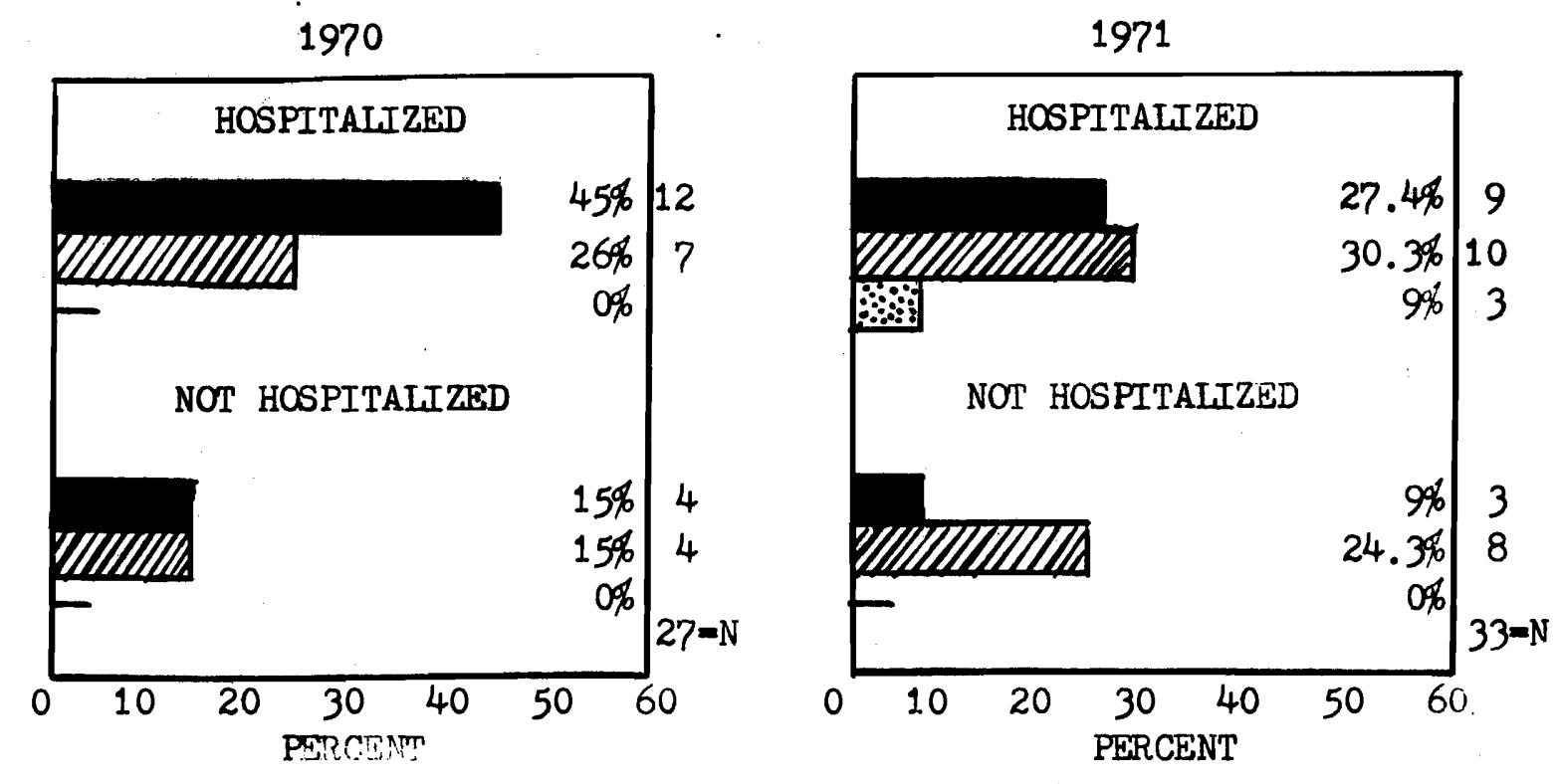

REMOVED

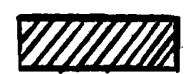

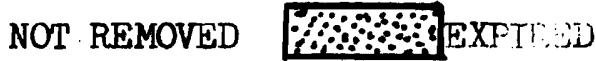

Table IX considers families receiving help as a result of the child's removal. In this study we found that $75.8 \%$ of all families received some kind of help. The Matusak study showed $70 \%$ in this same category. Considerably fewer children were removed in 1971 than in 1970. As in 1970 all children removed received agency help. Although a larger number of children 
remained in their own homes in 1971, more were reported as receiving help than not, a reversal of the 1970 findings.

TABLE IX

FAMILIES RECEIVING HELP AS A RESULT

OF CHILD BEING REMOVED

1970 AND 1971 STUDY GROUPS

1970

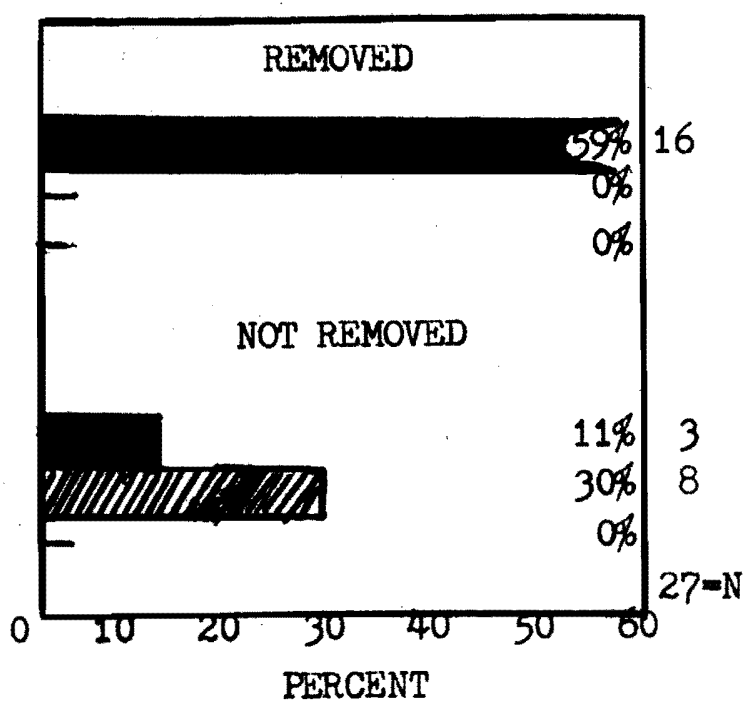

PERCENT

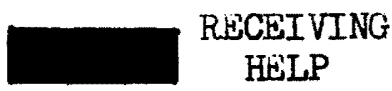

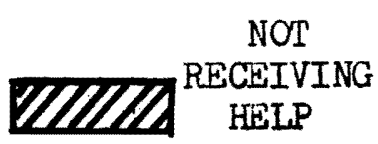

1.971

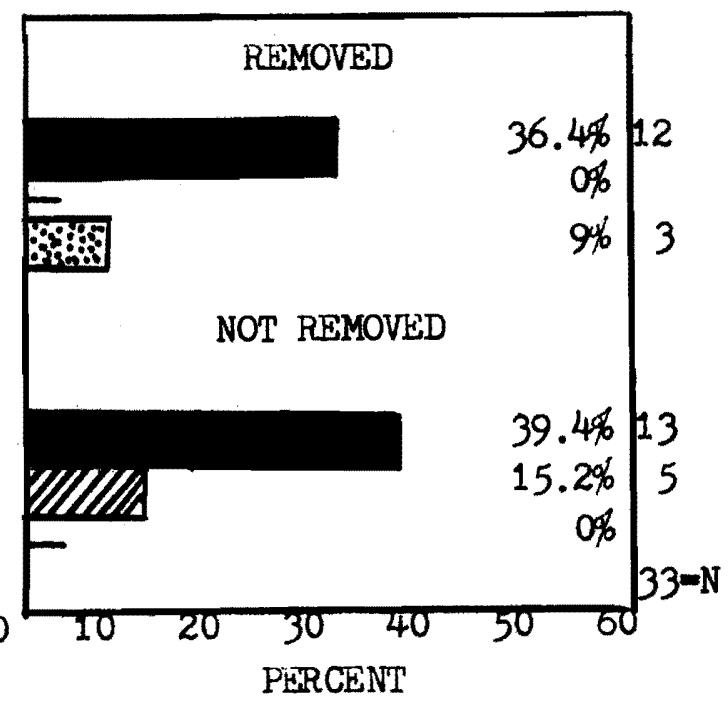

PXXPIRED

Situation improvement or lack of improvement, in each case, was rated according to the scale developed by Matusak:

1 - Total situation notably improved (child is safe and family functioning considerably better).

2 - Child is safe (such as in foster care); family situation same as at time of injury or very questionable.

3 - Repeated incidence of abuse (or neglect).

4 - Unknown (no known contact or whereabouts unknown).

5 - Situation very uncertain (very uncertain of child's safety and family's functioning very precarious even though agency is involved). 
One and two were considered as improvements; three and five were seen as not improved and four is in its own category and not considered good.

Table X shows that $11(61 \%)$ of the children who were left in their own homes remain in an uncertain or precarious situation (i.e. the safety of the child is questionable). The situation of another three (16\%) is unknown. Only $4(22.3 \%)$ have shown improvement. All who showed improvement received serious injury and received agency help. Of the 18 children left in their own homes, 4 of those seriously injured received no help and their situation is either unknown or precarious.

A rating of improvement denotes only that the child is safe. If the child has been removed from his home, the family may or may not be receiving service directed toward rehabilitation. If a child is in his own home and also is rated as improved, there has been some change which makes the environment safer for the abused child. Changes wich could account for this might include: (1) separation from the perpetrator of abuse, (2) active involvement of parents in mental health or public health programs.

TABLE X

CHILDREN IN OWN HOMES: IMPROVEMENT AS RELATED TO SERIOUSNESS OF INJURY AND AGENCY HELP 1970 AND 1971 STUDY GROUPS

\begin{tabular}{|c|c|c|c|c|c|}
\hline \multirow[b]{2}{*}{ Rating } & \multirow{2}{*}{$\begin{array}{l}\text { No. of } \\
\text { Cases } \\
\end{array}$} & \multicolumn{2}{|c|}{ Serious } & \multicolumn{2}{|c|}{ Non-Serious } \\
\hline & & Help & No Help & $\underline{\mathrm{Help}}$ & No Help \\
\hline 1 & 4 & 4 & 0 & 0 & 0 \\
\hline 2 & 0 & 0 & 0 & 0 & 0 \\
\hline 3 & 0 & 0 & 0 & 0 & 0 \\
\hline 4 & 3 & 0 & 2 & 0 & 1 \\
\hline 5 & 11 & 4 & 2 & 4 & 1 \\
\hline
\end{tabular}

TOTAL $\quad 18$

${ }^{8}$ Matusak, op. cit., p. 19. 
The data presented in Table XI relates the improvement of the child's situation to the receiving of agency help. Of the 1971. study group only those children who received agency help showed improvement and they represented $45.7 \%$ of the total group. Also receiving agency help but not showing improvement were $24.1 \%$ of the total group.

The same compilation of data and rating was made of the 1970 study group insofar as the present situation could be determined. We find that $51.9 \%$ of these children are still receiving agency help as compared with 71\% reported as receiving help in 1970 . Whereas $56 \%$ were reported in the 1.970 study as improved, the figure has dropped to $40.8 \%$ for 1971 . Of those not receiving agency help there is an increase from $7 \%$ in 1970 to $11.1 \%$ in 1971 considered improved.

\section{TABLE XI}

IMPROVEMENT OF CHILD'S SITUATION

IN RELATION TO AGENCY HELP

1970 AND 1971 STUDY GROUPS

\section{CASES AS OF 12-31-70}

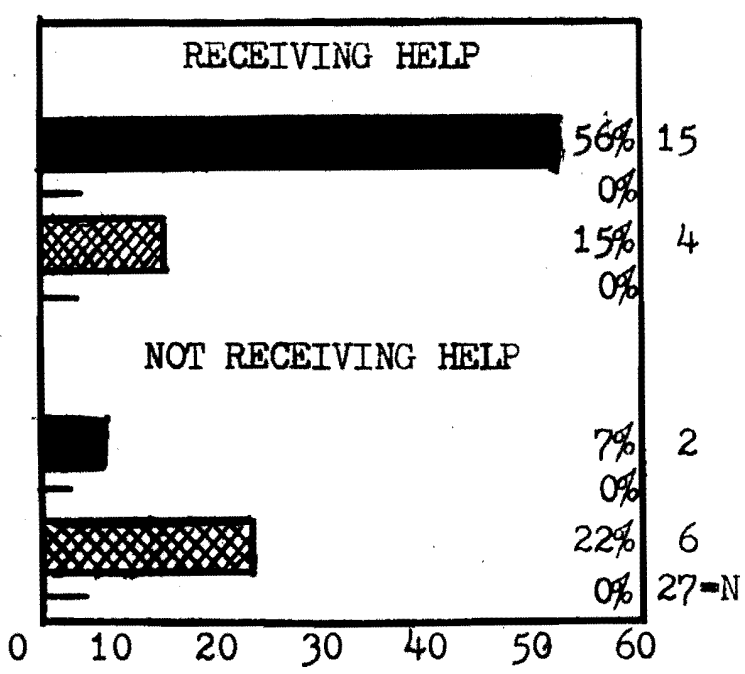

PERCENT
1970 CASES AS OF 12-31-71

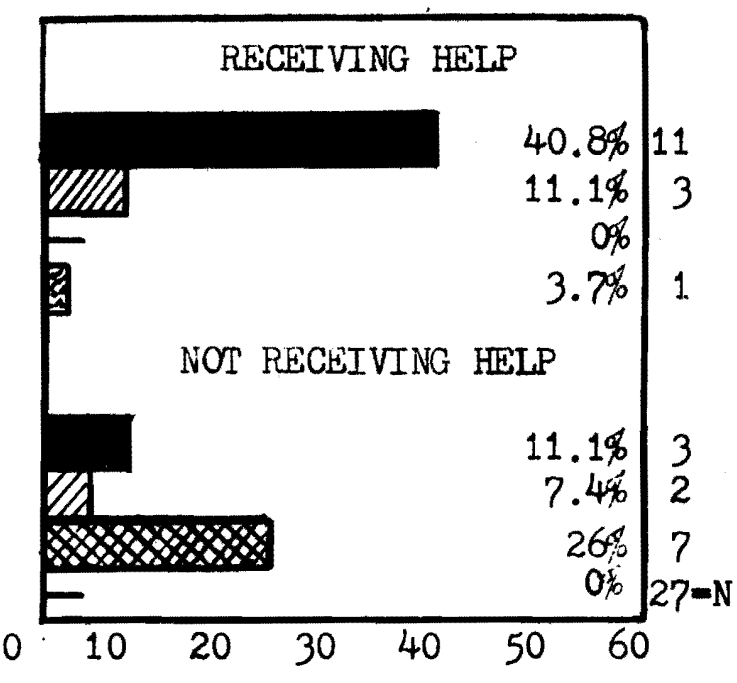

PERCENT 
TABLE XI (Continued)

1971 CASES AS OF 12-31-71

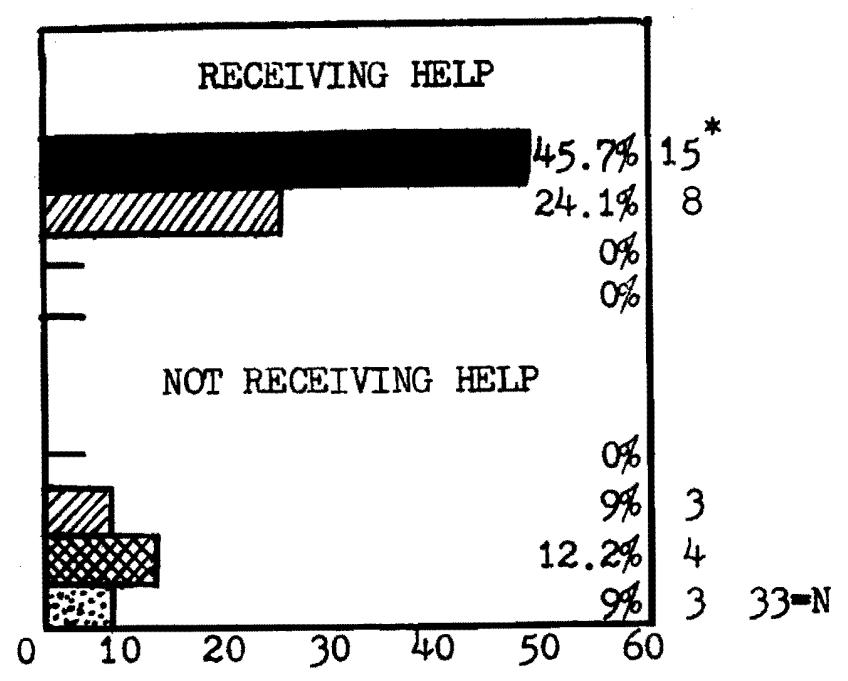

IMPROVED

NOT IMPROVED UNKNOWN

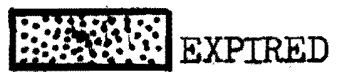

*Includes adoptive planning for $3(\% \%)$.

Table XII considers the seriousness of injury to improvement or lack of improvement. The 1971 study group shos $36.4 \%$ of the children showing improvement received serious injury.

In the Matusak study $44 \%$ of the children showing improvement received serious injury. For the same study group, the number drops to $40.8 \%$ one year later in a similar comparison of seriousness of injury and improvement.

The 1971. study shows a downward trend in improvement of children with serious injury as well as those with non-serious injury. In taking a look at combined figures of improvement (serious and non-serious injury) the failure to maintain improvement is startling. It drops from $68 \%$ in 1970 to $51.8 \%$ in 1971 . for the Matusak study group. An even lower rate of improvement $(45.4 \%)$ is shown for the 1971 study group. 
TABIE XII

SERIOUSNESS OF INJURY RELATED

TO IMPROVEMENT OR LACK OF IMPROVEMENT

1970 AND 1971 STUDY CASES

1970 CASES AS OF 12-3-70

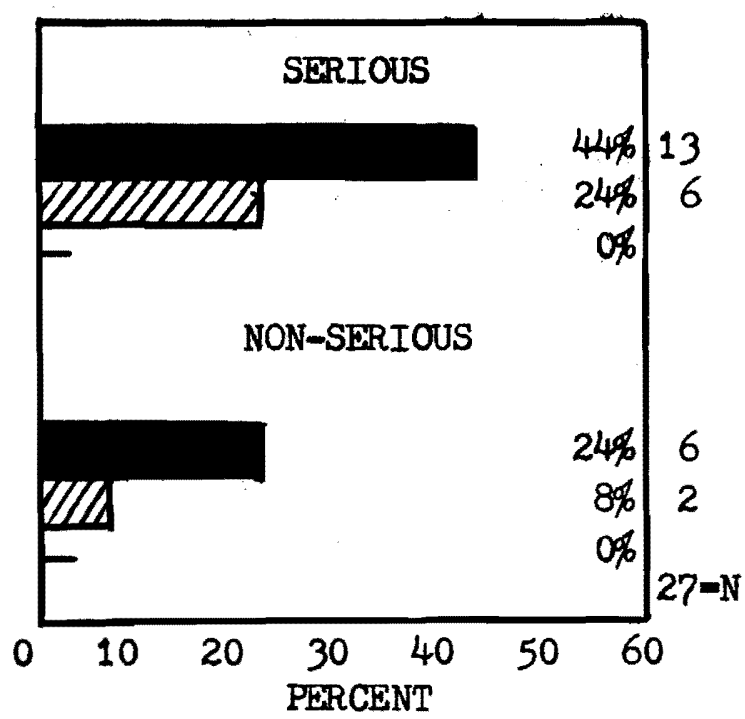

1970 CASES AS OF 12-31-71

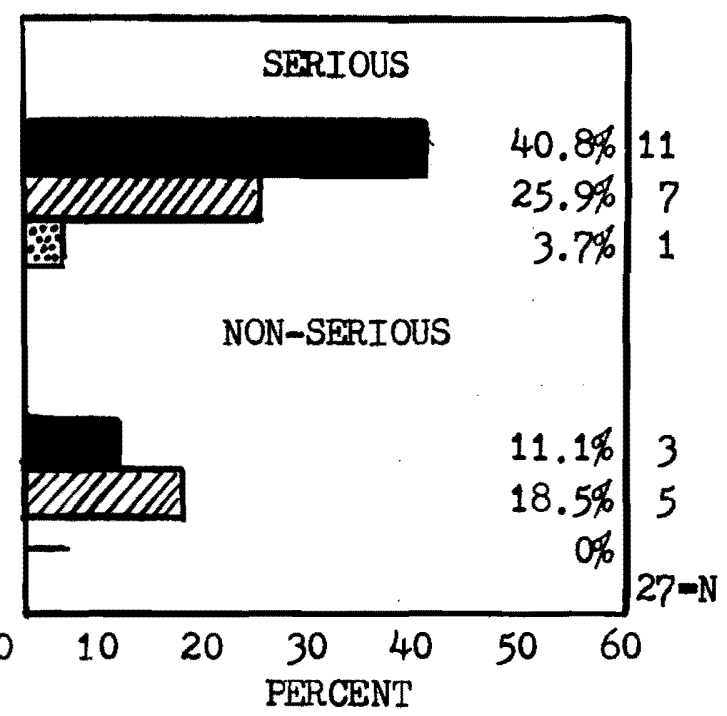

1971 CASES AS OF 12-3--71

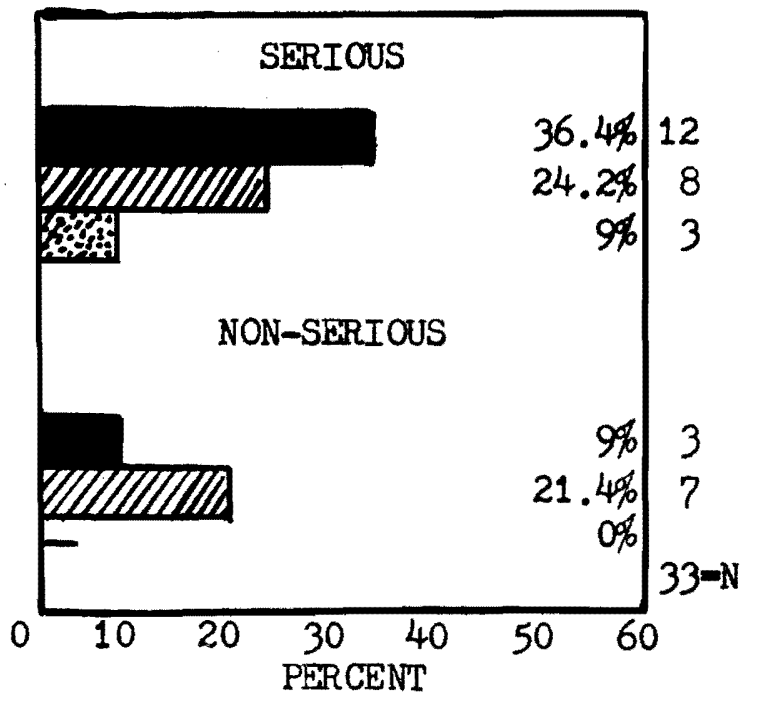

IMPROVED 


\section{DISCUSSION}

This study is Iimited to a group of children seen at UOMS and identified as abused. Though UOMS serves the entire state of Oregon, most of the patients in this study are residents of the Portland Metropolitan area. 9 These children come primarily from multi-problem families who have experienced a considerable degree of socio-economic deprivation. It is recognized that the children seen at this hospital represent only a portion of the total number of children identified as abused in the geographic area served by the hospital.

Because the characteristics of the patient load at UOMS may be unique and not representative of the area-wide population, any attempt to generalize the findings of this study to the entire metropolitan area would be seen as lacking validity.

Many studies of child abuse have included compilations of data relating to the age of children and seriousness of injury. ${ }^{10}$ These studies generally support the point of view that the very young child is particularly vulnerable to serious injury. The findings of this study are consistent with those of other researchers as we note that the greater proportion of children are under two and an increasing number of these are under one year of age. There is a corresponding increase in serious injury of the children under one. A hospital based study may misrepresent the picture somewhat in that more young children may be seen at the hospital because

9 Metropolitan area as used in this study includes Multnomah, Washington and Clackamas counties.

10 Elizabeth Elmer, "Identification of Abused Children," Children, 10:5 (September-October 1963), p. 183; Ray T. Helfer and C. Henry Kempe, eds. . The Battered Child, p. 29. 
of the vulnerability factor. ${ }^{11}$

Although most of the children come from two parent families, this in no way implies a stability in family relationships. ${ }^{12}$ In considerIng both one parent and two parent families in this study, we find in some cases a history of drug use, considerable mobility and with others a history of commanal living. Related to these factors is lack of attention to good nutrition and health practices. Other parents are retarded; some are severely disturbed with diagnosed mental disorders. Many have been battered themselves as children. Most are inadequate in parenting ability. 13

Only two stepparents are represented in this study, but it may be significant to note that they were both perpetrators of the abuse.

Kany cases of child abuse are so clear cut that there is no doubt about the need to file a Report. In other cases it is more difficult to make a decision. It is in relation to this latter category the Committee peforms one of its primary functions, that of making a decision as to whether a report should be filed. The proportion of reports filed to the number of cases in each study year has remained nearly the same. However, there was in 1971 a decrease in the number of wardships in relation to reports filed. The reasons for this are not always clear. Failure to establish wardships may in some cases seriously jeopardize a child's welfare.

${ }^{11}$ David G. Gil, Violence Against Children, (Cambridge, Mass.: Harvard University Press, $1 9 7 0 \longdiv { \text { , p. } 1 0 5 . }$

12 Joan Court, "Psycho-Social Factors in Child Battering," Journal of the Medical Woman's Federation, (April 1970), p. 99; Helfer and Kempe, op. cit., p. 107 ; Leontine Young, Wednesday's Child, p. 73.

13Alice E. Glazier, Child Abuse, (East Aurora, N.Y.: Henry Stewart, 1971), p. 145. 
This is assuming that wardship carries with it an order providing for appropriate protective services.

An illustration of this point is the case of an infant first admitted to the hospital immediately after his delivery at home. He was removed, against modical advice, from the hospital by his parents the next day. When he was five months old his parents reported an exposure to tuberculosis in the commune where they were then living. Because a skin test showed a positive reaction and there was X-ray evidence of an active primary infection, he was hospitalized. The parents remeined unconcerned over the modical implications of the findings and refused to cooperate in administering the necessary medication after his release from the hospital. Clinic appointments were not kept. A Report was filed. The public health nurse attempted to follow the child at home but the family moved. It was only after a lapse of several months that the child and his parents were located in another commune. The child was again hospitalized; an order placing the child in temporary custody of the hospital was obtained. However, the parents were successful in obtaining a dismissal of the order and the child was released from the hospital to them. Again they failed to keep clinic appointments. They were later located in another part of the state but fled after one contact by the public health nurse. The case is now closed due to inability to locate the child. The parental neglect seems quite obvious but community agencies were without the authority to provide necessary protection for the child.

Fewer of both hospitalized and non-hospitalized children were removed from their own homes in 1971 than in 1970. Of the 18 children who remained in their own homes, one was made a court ward. She was seriously injured and has required intensive follow up services because of continuing medical 
needs. Her situation is rated as improved. Three other seriously injured children also are rated as improved, They also received agency help.

The status of three children is unknown. Two were last to contact because of lack of parental cooperation. Both had serious injuries. The third case, classified as non-serious injury, was closed following the initial investigation. However, the researchers question the judgment of this in view of the recorded history of harsh discipline by the father.

The status of 11 children remaining in their own homes is unimproved or uncertain. The situation of some of these is precarious. Whereas six received serious injuries, only four received agency help while of the five shown with non-serious injury, four received agency help. One questions why the authority and responsibility for providing protective services was not more consistently provided. Perhaps the rate of improvement and the ability to maintain contact might have been proportionately higher.

It is to be noted that all children removed from their homes received agency help. It does not necessarily follow that the family received help. In many cases they did not. This points up the inequities of planning and management for families of children who have been abused.

An important part of this study was an attempt to assess improvement of children in the Matusak study over time. The researchers experienced a great deal of difficulty in determining agency involvement and in contacting agency personnel with responsibility for cases. The data as compiled is thought to be reasonably accurate. It was disappointing to note that although half the children were still receiving help from an agency this was considerably less than reported in 1970. Furthermore, the level of 
improvement had not been maintained, dropping from $56 \%$ to $40.8 \%$. It is difficult to ascertain with any degree of accuracy the true picture of improvement of individual children over time. The children now reported as improved are not in all instances the same as those reported improved a year earlier.

When comparing situation outcome for children of the Matusak study in the years 1970 and 1971, the thing that stands out is the failure to have maintained the same high level of improvement. Of further concern is the fact that the situation outcome for the 1971 study group shows a considerably lower rate of improvement than did those of the Matusak study for either year.

The seriously injured children in this study totaled 23 as compared. to 19 in the Matusak study. Not only does this represent an increase of $21 \%$ over the previous count but three of these four children were so seriously injured that they died during hospitalization. Though the Matusak study reported no deaths in the 1970 study group, one of these children died during the ensuing year. The death, however, was not attributed to the abuse. This child had serious congenital health problems which required specialized medical care available at the UOMS and not in the small Iastern Oregon community from which she came. Following a period of hospitalization and foster care she was returned to her parents in Eastern Oregon. There were serious questions as to whether this multi-problem family, reportedly retarded, mentally disturbed and drug addicted, could provide adequate care for this child. Due to the close collaboration of the public health nurse, the Public Welfare social worker and the family medical doctor, it was possible to provide well coordinated and appropriate services to this fanily and the parents were able to provide adequate care for their child. The 
social worker with whom the researcher talked, expressed very warm and positive feelings toward this family, stressing the fact that the death was due to medical problems and not due to neglect or abuse. This illustrates the concept that when intensive follow up services are available and they are properly coordinated some very marginal families are able to respond to a far greater degree than might be anticipated.

\section{The Interview Questionnaire}

The researchers are of the opinion that the use of an interviewquestionnaire such as they attempted could be a useful research tool. The objectives of the questionnaire in this study were not achieved for a number of reasons. The most significant factor was the inability to interview a sufficient number of parents to be able to generalize findings to the total study population and to determine with any degree of accuracy how parents feel about services provided or how they could be improved. Repeated unsuccessful attempts were made to locate and interview the parents of children in the 1970 study group. In some instances the family had moved leaving no information as to their whereabouts. The unscheduled nature of the visits probably contributed greatly to the failure of this part of the study.

Five interviews were completed. In each case it was the mother who provided the information. No attempt was made to tabulate data from the interviews. The small number of completed interviews precludes a valid generalization to the total study population. A contact with the parents of one child resulted in a refusal to participate in any type of study. Their resistance appeared to be related to a recent incident of abuse (beyond the study period) and fear of agency involvement. This refusal to 
participate in the study seems contradictory to the experience of Deschin who states, "Most human beings ... are likely to share significant... data at a time of stress if the data sought in the interview are related to the stress from the point of view of the respondent!" ${ }^{14}$

There seemed to be certain factors common to the families who were interviewed. None appeared reluctant to participate in the interview. All were two parent families and from a lower socio-economic level. In all cases a child abuse report had been filed. Without exception, these parents expressed satisfaction with medical service provided at the Medical School and they continue to use those facilities to meet their modical needs.

Three of the mothers expressed criticism of professional personnel (hospital social worker and public health nurse) who, they felt, failed to give consideration to feelings they were experiencing as a result of the incident of abuse and what followed.

The child of one mother interviewed had experienced several accidents requiring medical attention, each of which was attributable to lack of parental supervision. A particularly bizarre aocident almost cost her life. It is interesting to note that this mother, in spite of her shortcomings, felt that she would have benefited from "psychiatric" help in knowing how to deal with her child's feelings in relation to this particularly traumatic incident.

In retrospect, were the researchers to undertake such an interview questionnaire again they would modify procedures. In particular, it now

${ }^{14}$ Celia S. Deschin, "Some Further Applications and Suggested Principles", Research Interviewing in Sensitive Subject Areas, (N.Y.: NASW, 1963), p. 21. 
seems that a letter ${ }^{15}$ should have been sent to each family telling them that someone would be coming to see them. An additional purpose of the letter would be to state the reason for the visit and to request their help in making an evaluation of services to patients at UOMs and possible ways services to children and their families might be improved. 16

Because of the difficulties encountered in finding people home it might be helpful to provide a simple means by which the family could indicate when they might be available to the researcher.

${ }^{15}$ See Appendix for letter used as an introduction to questionnaire. 16 Elizabeth Elmer, Children in Jeopardy, (Pittsburgh, Pa.: University of Pittsburgh Press, 1967), p. 10. 
SUMMARY AND RECOMMENDATIONS

This study evolved out of the Matusak study of 1971 and has as its primary purpose an evaluation of the effectiveness of help being provided to abused children and their fantlies. As the data were compiled and compared to the Matusak study the consistency with respect to certain factors was remarkable. For example, the majority of children in each of the three study groups fell in the under two age range, a partioularly vulnerable period. ${ }^{17}$ The findings of both this study and the Matusak study that the majority of child abuse cases are from two parent families is consistent with the family composition as reported by other researchers. ${ }^{18}$ Two parent families continue to account for the greater number of serious injuries.

There was a comparable number of Reports filed in the two study years but this study discloses a decrease in both the number of children made court wards and in the number of children removed from their parental homes. The researchers are unable to identify the reasons for this.

The documentations in the Matusak study seemed to indicate a trend toward more effective management leading to an improved situation in terms of the safety and welfare of the child. Unfortunately, this hopeful trend has not held in the current year. Although the number of families reported as receiving help has risen slightly in the 1971 study group, there has not been 2 corresponding rise in the number of those whose situation is considered improved. Not only has the 1970 group failed to maintain its level of improvement, but the 1971 group shows even less improvement.

17C. Henry Kempe and Ray E. Helfer, eds., Helping the Battered Child and His Family, p. 77; Serapio R. Zalba, "The Abused Child: I. A Survey of the Problem," Social Work, (October 1966), p. 6. p. 117.

18 Vincent J. Fontana, The Maltreated Child, p. 17; Glazier, op. cit., 
The obstacles noted in the Matusak study as interfering with effective management of child abuse cases still exist. Although the Committee can and does identify the abused child, makes reconmendations for treatment and follow up, it carries neither authority nor responsibility to act in other than an advisory capacity.

An area of concern to the researchers is the evidence of inadequate coordination of services in the community. Often more than one agency is working with a family, unaware of services being provided by others. This segmented approach does not resolve the basic problems contributing to the abuse. It is apparent that a need exists to clarify and to define the responsibility and limitations of the individuals and agencies involved in cases of abuse, both in the community and in the hospital setting. There is a vital need for the utmost cooperation and collaboration of all those involved with this problem. In order to achieve this, one agency should have both the responsibility and the authority to act as coordinator in services to the abused child.

There are usually only three alternatives for the child who has been abused: (1) return to the family, (2) foster home care, and (3) termination of parental rights which would make adoption possible. The option available to any particular child may be dependent on the concern, knowledge and skill of the social worker. We must recognize, however, that not every agency person is able to accept and to deal with the very difficult task of helping parents of abused children. The researchers feel consideration should be given to the development of a specialized unit to handle cases of child abuse. This unit should be staffed by carefully selected personnel who, through specialization, can acquire the expertise and consistency which should be a part of case management and treatment. 
Logically, it would seem that Children's Services Division, with its legal mandate ${ }^{19}$ to provide protective services to abused children, should be the agency to develop this specialization. Silver, ${ }^{20}$ who did a study of the roles played by individual agencies and the effectiveness of agency intervention in cases of child abuse, supports the belief that all families suspected of child abuse should be referred for protective services.

One of the more disturbing aspects of the child abuse problem as seen by the researchers was the realization that there were abused children who were lost to further contact and follow up services because parents had fled with them from the state. One such case was that of an eighteen months old child who had come with his father to Portland from an eastern state. The child suffered critical injuries, allegedly at the hands of a baby sitter (also reported to be the father's girl friend). A few days following his release from the hospital he was taken out of state by the father. This occurred in spite of pending Juvenile Court action. Whereabouts was unknown until an inquiry came from a California hospital to UONS requesting medical information. The child was seriously ill, badly bruised, and hospitalized. He was followed briefly by a social worker. Again the father and child disappeared shortly after hospital discharge. Whereabouts remains unknown. The number of times this child may be hospitalized in the future without medical knowledge of previous injuries or illnesses suggestive of abuse is open to conjecture.

${ }^{19}$ State Law enacted by House Bill 1754 in 1971, revising and amending ORS 146.710-146.990 and 419.476.

20 Larry B. Silver, Christina C. Dublin, and Reginald S. Lourie, "Agency Action and Interaction in Cases of Child Abuse, "Social Casework (March 1971), p. 170. 
Many states have recognized the importance of a central registry of child abuse cases. Since circumstances of known abuse are suggestive of prior abuse and of a potential for further abuse, this offers some protection to these children within the state. A registry of national scope would provide even greater protection for those children whose parents take them in flight from state to state to avoid the consequences of the abusive act. ${ }^{21}$ In consideration of the sophistication of present day computerized equipment, it would seem that such a system could be developed.

The members of the Committee have assumed an important role in focusing their attention to the early identification of child abuse cases and in undertaking to coordinate services to them. It seems obvious that there is a need for the Committee to continue to function as a decision making body in matters pertaining to the filing of reports and to be concerned with administrative problems related to the child within the medical setting. Their role in the providing of an ongoing educational program for hospital staff is seen as of primary importance. Their experience places them in a key position for the identifying of areas for research and for obtaining the necessary means for implementing that research. The community should be able to look to them for competent guidance in any effort made in behalf of abused children.

Child abuse must be recognized by the comminity as a problem of increasing incidence and importance. Service to children and their families must not be mere "watchfulness" but should be actively directed toward provision of safety for the child and rehabilitation of the parents. This can be accomplished only through the utilization of all community resources with authority and responsibility for coordination invested in a single agency. 


\section{BIBLIOGRAPHY}

Child Welfare League of America. The Neglected Battered-Child Symdrome, Role Reversal in Parents. New York: Child Welfare League of America. July 1963.

Children's Division, American Humane Association. Child Protective Services - 1967, a National Surver. Denver, Colorado: American Humane Association.

Cochrane, W. A. "The Battered Child Syndrome." Canadian Journal of Public Health, 56 (May, 1965), 1.93-196.

Court, Joan. "Psycho-social Factors in Child Battering." Journal of the Medical Woman's Federation, 52 (April, 1970), 99-104.

DeFrancis, Vincent, J. D. Child Abuse Legislation in the 1970's. American Humane Association, Children's Division. Denver, Colorado.

Deschin, Celia S. "Some Further Applications and Suggested Principles." Research Interviewing in Sensitive Subject Areas. N.Y.: National Association of Social Workers. 1963. 19-23.

Elmer, Elizabeth. Children in Jeopardy. Pittsburgh, Pa.: University of Pittsburgh Press. 1967.

Elmer, Elizabeth. "Identification of Abused Children." Children. 10:5. (September-October, 1963), 180-4.

Fontana, Vincent J. The Maltreated Child: The Maltreatment Syndrome in Children. Ed 2. Springfield, Illinois: Charles C. Thomas, Publisher. 1971.

Galdston, Richard. "Observations on Children Who Have Been Physically Abused and Their Parents." American Journal of Psychiatry. 122:4 (October, 1965), 440-443.

Gil, David G. Violence Against Children. Cambridge, Mass.: Harvard University Press. 1970.

Gil, David G. and Noble, John H. "Public Knowledge, Attitudes and Opinions About Physical Abuse in the U. S." Child Welfare, XIVII (July, 1969), 395-401.

Helfer, Ray E. and Kempe, C. Henry. eds. The Battered Child. Chicago, I11.: University of Chicago Press. 1968.

Helfer, Ray E. and Pollock, Carl B. "The Battered Child Syndrome." Advances in Pediatrics, 15 (September, 1968), 9-27.

Holter, J. C. et al. "Child Abuse: Early Case Findings in the Emergency Department." Pediatrics, 42 (July, 1968), 128-38. 
Ireland, William H. "A Registry on Child Abuse." Children, 13:3 (MayJune, 1966) 113-15.

Kempe, C. Henry and Helfer, Ray E. eds. Helping the Battered Child and his Family. Philadelphia, Pa.: J. B. Lippincott Co. 1972.

Matusak, Marguerite. "Follow Through Services for Child Abuse Cases." (Unpublished M.S.W. research practicum, Portland State University, 1971).

Paulsen, Monrad G. "Legal Protections Against Child Abuse." Children. 13:2 (March-April, 1966) 42-48.

Paulson, Morris J. and Blake, Phillip R. "The Physically Abused Child: A Focus on Prevention." Child Welfare. XLVII, (February, 1969) 86-95.

Rubin, Jean. "The Need for Intervention." Public Welfare. 24:3 (JuIy, 1966) $230-35$.

Silver, Larry B., Dublin, Christina C. and Lourie, Reginald S. "Agency Action and Interaction in Cases of Child Abuse." Social Casework. 52:3 (March, 1971) 164-171.

Simmons, Harold E. Protective Services for Children: A Public Social Welfare Responsibility. Sacramento, Calif.: General Welfare Publications, 1968.

Young, Leontine. Wednesday's Children. N. Y.: McGraw-Hill. 1964.

Zalba, S. R. "The Abused Child. A Survey of the Problem." Social Work. 11:4 (October, 1966), 3-16. 
APPENDIX 
Farch 20, 1972

The Univereity of Oregon Medical School has a continuing interest in children tho have been served in any way by the hospital. At the time your child was ruder our care there was concern about the nature of the illness or injury. We know that the kind of problem that caused your child to require treatment usually calls for considerable readjustment for both child and parent. There may have been people from several agencies who were involved with you and your child either during hospital treatment or since. In order to improve upon services we offer to children and their families we need to know who gave you the most help in readjustment. It would help us if you would oomplete the following questionnaire:

Richard !. Olmsted, M.D.

Chairman

Department of Pediatrics

I. Hospital Treatment period.

(a) Why do you think your child was first seen at the hospital?

(b) What was the diagnosis when your child was discharged?

iversity of Oregon

Medical School

Hospital

Doernbecher

emorial Hospital

for Children

-

11tnomah Hospital -

University

:ate Tuberculosis

Hospital

ral Outpatient Clinic

Julius L. Meier

Memorial Clinic

in Tuberculosis .

John E. Weeks

Institute for

e Advancement of

(c) At time of discharge were any special recommendations made?

By whom? What were they? 
II. Sources of Atency Help.

(a) Please list those agencies or persons you remember as having been involved with you and your child during hospital treatment and since.

(b) While your child was under hospital treatment

1. Who was most helpful to you?

a. What kind of help was offered?

2. Who vas the least helpful?

a. What kind of help was offered?

(c) Since hospital discharge

1. Have you had help from anyone?

2. Who has been most helpful?

a. What help was offered?

3. Who has been least helpful?

a. What kind of help was offered?

4. How long was help available to you?

5. How long do you feel you needed help? 
6. What else could have been done to help yous

d.

1. What fecommendations can you make that would help us provide better service to others?

0. 1. What problems do you have now in relation to your child?

2. Do you feel differently about your child nowrthan when first treated at the hospital? In what way?

1. Do you know if a report about your child's injuries was filed with the police or other authorities?

1. How did you leam about it?

2. Did the police talk to you about what happened?

3. How did you feel about that? 